\title{
A meta-analysis of everolimus-eluting stents versus sirolimus-eluting stents and paclitaxel-eluting stents in diabetic patients
}

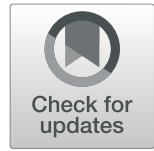

Hang Ouyang ${ }^{1}$, Xuehui Zeng ${ }^{1}$, Chunlei Zhang ${ }^{1}$, Linli Song ${ }^{1}$, Jiarui Xu' ${ }^{1}$, Zhihui Hou${ }^{1}$, Siya Xie ${ }^{1}$, Zheng Tao ${ }^{2^{*}}$ and Jincai He $\mathrm{1}^{*}$

\begin{abstract}
Objective: We performed this meta-analysis to determine which stent among everolimus eluting stents (EES), sirolimus eluting stents (SES) and paclitaxel eluting stents (PES) should be preferred for the treatment of DM patients.

Methods: A systematic search of publications about randomized controlled trials (RCTs) focused on diabetic patients received EES, SES or PES was conducted. We evaluated the following indicators: target vessel revascularization (TVR), target lesion revascularization (TLR), late luminal loss (LLL), stent thrombosis (ST), myocardial infarction (MI), all-cause mortality and cardiac mortality.

Results: EES showed obvious advantages over SES for DM patients, as it induced the lowest rate of target vessel revascularization and target lesion revascularization (TLR) $(p=0.04)$. In addition, EES induced lower in-segment LLL than PSE and SES and lower in-stent LLL than PES in DM patients (all $p<0.05$ ). Moreover, EES effectively reduced all-cause mortality compared to SES (RR $=0.71,95 \% \mathrm{Cl}: 0.52-0.99, p=0.04)$ and MI rates compared to PES ( $\mathrm{RR}=0.44$, $95 \% \mathrm{Cl}: 0.26-0.73, p=0.0002$ ). Furthermore, EES could reduce the ST rate compared with both SES (RR $=0.53,95 \%$ Cl: $0.28-0.98, p=0.04$ ) and PES (RR $=0.18,95 \% \mathrm{Cl}: 0.07-0.51, p=0.001)$.
\end{abstract}

Conclusion: Among those three types of stents, EES should be the first recommended stent for DM patients.

Keywords: Sirolimus-eluting stents, Paclitaxel-eluting stents, Everolimus-eluting stent, Diabetes, Meta-analysis

\section{Introduction}

Cardiovascular complications are the main cause of mortality among diabetes mellitus (DM) patients. It has been reported that almost half of DM patients undergo percutaneous coronary intervention (PCI) after diagnosis [1]. Moreover, although little difference between patients with and without DM was observed in the early stage

\footnotetext{
* Correspondence: taozheng67@foxmail.com; sztcmhjc@163.com

${ }^{2}$ Department of Vascular Surgery, Affiliated Hospital of Jiangsu University, 438 Jiefang Road, Zhenjiang, Jiangsu 212001, People's Republic of China 'Department of Clinical Laboratory, Shenzhen Traditional Chinese Medicine Hospital, The Fourth Clinical Medical College of Guangzhou University of Chinese Medicine, 1 Fuhua Road, Shenzhen, Guangdong 518033, People's Republic of China
}

after PCI, patients with DM often had a worse prognosis and higher rates of restenosis, multivessel revascularization and revascularization than those without DM [2-4].

Some randomized controlled trials (RCTs) found that EES and SES showed comparable overall safety and efficacy, and both were better than PES [5, 6]. For DM patients, as reported by Conder in 2017, EES has significant advantages over other stents, including SES and PES, and therefore is recommended as the priority choice of DM patients undergoing PCI. However, another RCT demonstrated that EES had an increased trend in the rate of target lesion revascularization (TLR) than PES for DM patients who received insulin

(c) The Author(s). 2021 Open Access This article is licensed under a Creative Commons Attribution 4.0 International License, which permits use, sharing, adaptation, distribution and reproduction in any medium or format, as long as you give appropriate credit to the original author(s) and the source, provide a link to the Creative Commons licence, and indicate if changes were made. The images or other third party material in this article are included in the article's Creative Commons licence, unless indicated otherwise in a credit line to the material. If material is not included in the article's Creative Commons licence and your intended use is not permitted by statutory regulation or exceeds the permitted use, you will need to obtain permission directly from the copyright holder. To view a copy of this licence, visit http://creativecommons.org/licenses/by/4.0/ The Creative Commons Public Domain Dedication waiver (http://creativecommons.org/publicdomain/zero/1.0/) applies to the data made available in this article, unless otherwise stated in a credit line to the data. 
treatment [7]. Therefore, we performed this metaanalysis in order to evaluate whether EES is indeed a better stent for DM patients than SES and PES,

\section{Materials and methods}

\section{Search strategy}

In November 2019, we searched the PubMed, Cochrane, and EMBASE databases and CNKI, Wanfang, and Clinicaltrials.gov for all randomized controlled trials (RCTs) comparing EES with SES or PES. Complex search strategies were formulated and conducted after we selected the following Mesh terms as keywords: drug-eluting stents, everolimus, sirolimus, paclitaxel, first-generation, diabetic, and diabetes. An extensive search of the ISI Web of Science database using crossreferences from the eligible articles and relevant reviews was also conducted. The language of the articles was restricted to English and Chinese.

\section{Selection criteria}

RCTs about EES vs SES or EES vs PES that met the following inclusion criteria were included in the present study: (1) patients were diagnosed with diabetes; (2) clinical outcomes were reported; and (3) follow-up data lasted more than half a year. RCTs were excluded if they met any of the following criteria: (1) retrospective or nonrandomized trials; (2) some patients were not diabetic; (3) SES vs PES or indirect comparison between EES, SES or PES.

\section{Study enrolment and data extraction}

The two researchers (H.O. and X.Z.) independently performed the literature search and extraction of patient data, including baseline data and postoperative imaging data, and other follow-up results using predetermined standardized tables. Target vessel revascularization (TVR), target lesion revascularization (TLR), late luminal loss (LLL), stent thrombosis (ST), myocardial infarction (MI), all-cause mortality and cardiac mortality were recorded. If there was a disagreement between the two researchers, an independent third person resolved the problem according to the Cochrane collaboration [8]. If there were any incomplete or suspicious research data, we tried to resolve the issue by contacting the authors. We used the Cochrane Risk Bias Evaluation Tool to assess the quality of the included articles .

\section{Statistical analysis}

We used RevMan v5.3 (Copenhagen, The Nordic Cochrane Centre) to analyse all the collected results. Continuous results were recorded as dichotomous data, while LLL was recorded as the standardized mean difference (SMD). To avoid the influence of heterogeneity of the included trials on overall effects, we computed the risk ratios (RRs) and 95\% confidence intervals (CIs) with two-sided $P$-values for all results. Statistical significance was defined as $P<0.05$. The heterogeneity of the included RCTs was assessed using Higgins and Thompson's $\mathrm{I}^{2}$ statistic. When $\mathrm{I}^{2}>50 \%$, the heterogeneity of the RCT was considered high. All analyses were conducted under PRISMA guidelines [9]. Since we trying to confirm whether the application of EES in diabetic patients has obvious advantages, we also combined SES and PES as the first-generation stent for research to ensure that the conclusion is foolproof.

\section{Registration of the study protocol}

The protocol for this study was prepared prior to the start of the study and was registered in PROSPERO with identification number CRD42019130007.

\section{Results}

Selected studies and characteristics

The primary search identified 2903 articles, and 8 [7, 10-16] met the inclusion criteria and were therefore included in our study (Fig. 1). A total of 4047 DM patients were included, 1898 of whom were randomly located in the EES vs SES group, and the others were located in the EES vs PES group (Table 1). All basic features of the patients in each group are shown in Table 1. All patients were treated with DAPT for 6 months or 12 months under the protocol of treatment or research guidelines. The average age of the patients ranged from 58 to 68 years and the proportion of men ranged from 43 to $76 \%$ in the included RCTs. In addition, the incidence of acute coronary syndrome ranged from 31.9 to $53 \%$. Furthermore, three of the included clinical trials reported 12-month follow-up data $[7,10,12]$, one of them had 18-month follow-up data [11], and the others had follow-up data for $\geq 24$ months [13-16]. The duration of DAPT (dual antiplatelet therapy, DAPT) treatment was 6 months in two trials [7, 13] and 12 months in the others. The results of bias assessment are shown in Figs. 2 and 3.

\section{TVR and TLR}

TVR and TLR were employed in this analysis as indicators for the effectiveness of PCI. The TVR of the patients with EES was significantly lower than that of the patients with SES (RR $=0.69,95 \%$ CI: $0.48-0.98, p=0.04$ ) and that of the pooled data of SES and PES $(\mathrm{RR}=0.71, \mathrm{p}=0.04)$ (-. 4A). In addition, EES induced a lower TLR rate than SES ( $R R=0.70,95 \%$ CI: 0.50-0.98, $p=0.04$ ). However, although a reduced trend of TLR was observed in the DM patients with EES compared with the pooled data of the SES-treated and PES-treated patients $(\mathrm{RR}=0.69,95 \% \mathrm{CI}$ : $0.47-1.00, \quad p=0.05)$, no statistical significance was 


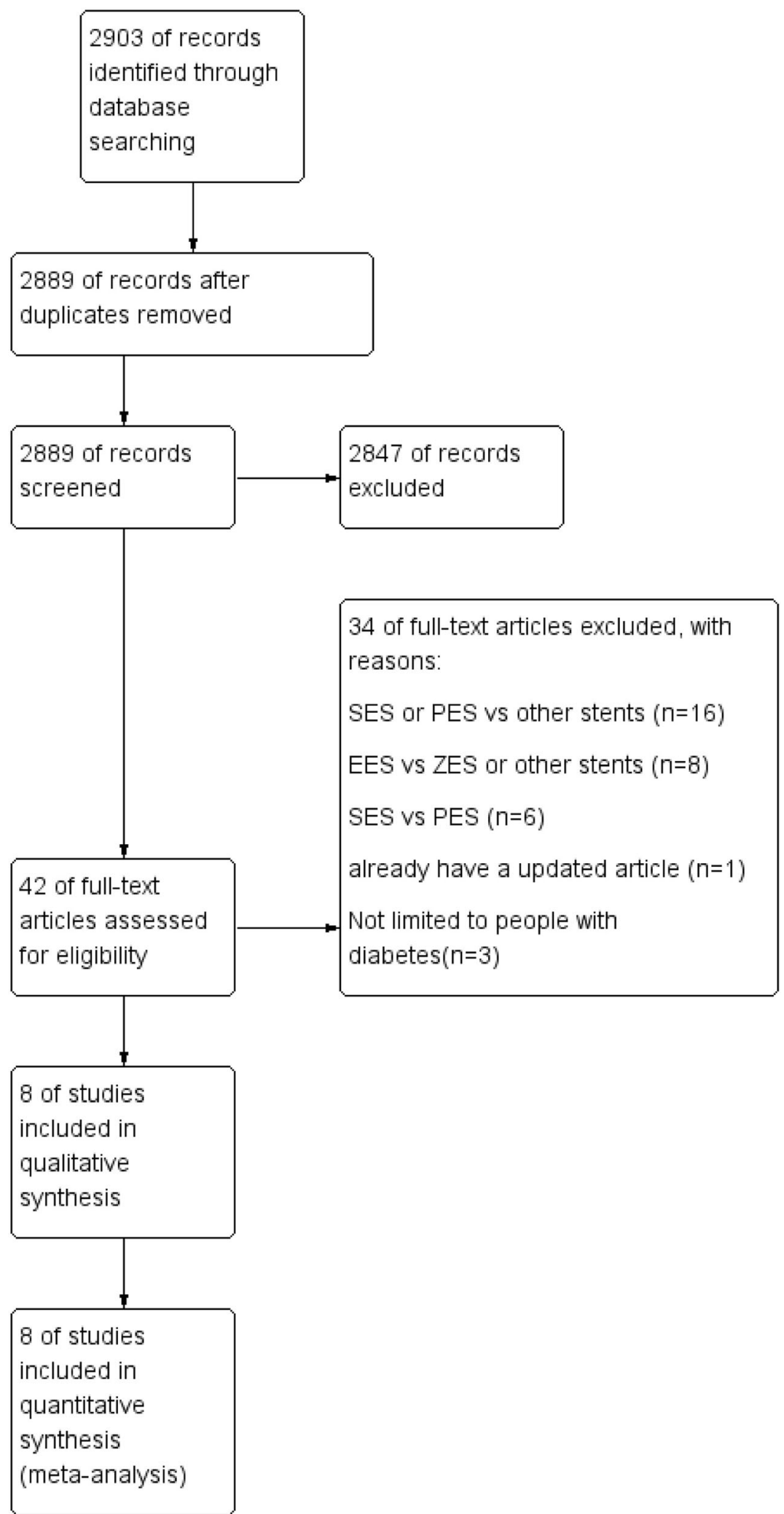

Fig. 1 Flowchart of the selection strategy and inclusion/exclusion criteria in the current meta-analysis. EES: everolimus-eluting stents, ZES: zotarolimus-eluting stents, PES: paclitaxel-eluting stents, SES: sirolimus-eluting stents 
Table 1 Baseline characteristics of the included trials

\begin{tabular}{|c|c|c|c|c|c|c|c|c|c|c|c|c|}
\hline Trial & $\begin{array}{l}\text { Published } \\
\text { years }\end{array}$ & $\begin{array}{l}\text { Comparison } \\
\text { arms }\end{array}$ & $\begin{array}{l}\text { Sample } \\
\text { size }\end{array}$ & $\begin{array}{l}\text { Follow- } \\
\text { up, } \\
\text { months }\end{array}$ & $\begin{array}{l}\text { DAPT } \\
\text { duration, months }\end{array}$ & $\begin{array}{l}\text { Mean } \\
\text { age, years }\end{array}$ & $\begin{array}{l}\text { Male, } \\
\%\end{array}$ & $\begin{array}{l}\text { Insulin } \\
\text { use, \% }\end{array}$ & $\begin{array}{l}\text { ACS, } \\
\%\end{array}$ & $\begin{array}{l}\text { Primary } \\
\text { endpoint }\end{array}$ & $\begin{array}{l}\text { Current } \\
\text { smoker, } \\
\%\end{array}$ & BMI \\
\hline BIOSCIENCE & 2015 & EES vs SES & $229 / 257$ & 12 & 12 & 68 & 76 & 32.9 & 45 & $\begin{array}{l}\text { Target lesion } \\
\text { failure, } \\
\text { Cardiac } \\
\text { death, TV-MI, } \\
\text { TLR }\end{array}$ & 22 & 29.5 \\
\hline $\begin{array}{l}\text { DiabeDES } \\
\text { IV }\end{array}$ & 2015 & EES vs SES & $108 / 105$ & 48 & 12 & 63 & $N R$ & NR & 31.9 & $\begin{array}{l}\text { In-stent late } \\
\text { luminal loss }\end{array}$ & 23 & 29.5 \\
\hline RACES-MI & 2015 & EES vs SES & $64 / 68$ & 36 & 12 & 61 & 68 & 37.1 & $N R$ & MACE & 26 & $N R$ \\
\hline $\begin{array}{l}\text { ESSENCE- } \\
\text { DIABETES }\end{array}$ & 2011 & EES vs SES & $149 / 151$ & 12 & 12 & 64 & 59 & 15.3 & 42 & $\begin{array}{l}\text { In-stent late } \\
\text { loss }\end{array}$ & 24 & $N R$ \\
\hline $\begin{array}{l}\text { ISAR-TEST-4 } \\
\text { Trial }\end{array}$ & 2013 & EES vs SES & 184/193 & 36 & 6 & 68 & 74 & 32.4 & 40 & $\begin{array}{l}\text { Cardiac } \\
\text { mortality, TV- } \\
\text { MI, TLR }\end{array}$ & 14.3 & NR \\
\hline $\begin{array}{l}\text { SORT OUT } \\
\text { IV }\end{array}$ & 2012 & EES vs SES & 194/196 & 18 & 12 & 64 & 74 & 32.1 & 33 & $\begin{array}{l}\text { Cardiac } \\
\text { mortality, MI, } \\
\text { ST, TVR }\end{array}$ & 22.8 & $N R$ \\
\hline SPIRIT V & 2012 & EES vs PES & $215 / 104$ & 12 & 6 & 65 & 43 & 17.2 & 37 & $\begin{array}{l}\text { In-stent late } \\
\text { loss }\end{array}$ & 16.4 & $N R$ \\
\hline Tuxedo & 2017 & EES vs PES & $916 / 914$ & 24 & 12 & 58 & 75 & 40.8 & 53 & $\begin{array}{l}\text { TVF, TV-MI, } \\
\text { TVR }\end{array}$ & 15 & 26 \\
\hline
\end{tabular}

DAPT dual antiplatelet therapy, ACS acute coronary syndrome, $B M I$ body mass index, EES everolimus-eluting stents, PES paclitaxel-eluting stents, $M I$ myocardial infarction, TLR target-lesion revascularization, MACE major adverse cardiac events, TV target-vessel, TVR target-vessel revascularization, ST stent thrombosis, TVF target vessel failure $N R$ not reported

obtained between the patients with EES and PES (RR = 0.97, 95\% CI: 0.23-4.11, $p=0.97$ ) (Fig. 4b).

\section{In-segment LLL and in-stent LLL}

Four of the eight RCTs reported the length of late luminal loss. EES induced lower in-segment LLL than SES (RR $=-0.12,95 \% \mathrm{CI}:-0.22--0.02, p=0.02)$ and PES $(R R=-0.10,95 \% \mathrm{CI}:-0.20--0.00, p=0.04)$ and the pooled SES and PES $(\mathrm{RR}=-0.12,95 \% \mathrm{CI}$ : $-0.18-$ $-0.05, p=0.0008$ ) (Fig. 5a). A high level of statistical heterogeneity was found in the analysis $\left(\mathrm{I}^{2}=79 \%\right.$ for the EES vs SES group). Similarly, less in-stent luminal loss was observed in the EES-treated patients than in the PES-treated patients $(\mathrm{RR}=-0.2,95 \% \mathrm{CI}$ : $-0.3-$ $-0.1, P<0.0001)$, and there was also a reduced trend in the pooled data of SES and PES $(R R=-0.12,95 \%$ CI: $-0.23--0.00, p=0.05$ ) (Fig. 5b).

\section{All-cause mortality and cardiac mortality}

EES significantly reduced all-cause mortality compared with SES ( $R R=0.71,95 \% \mathrm{CI}$ : 0.52-0.99, $p=0.04$ ) but not PES ( $\mathrm{RR}=0.88,95 \% \mathrm{CI}$ : $0.55-1.41$, $p=0.60$ ) (Fig. 6a) and showed a decreasing trend compared with the pooled data of overall firstgeneration DES including SES and PES ( $R R=0.76$, 95\% CI: 0.58-1.00, $\mathrm{p}=0.05$ ) (Fig. 6). In addition, no

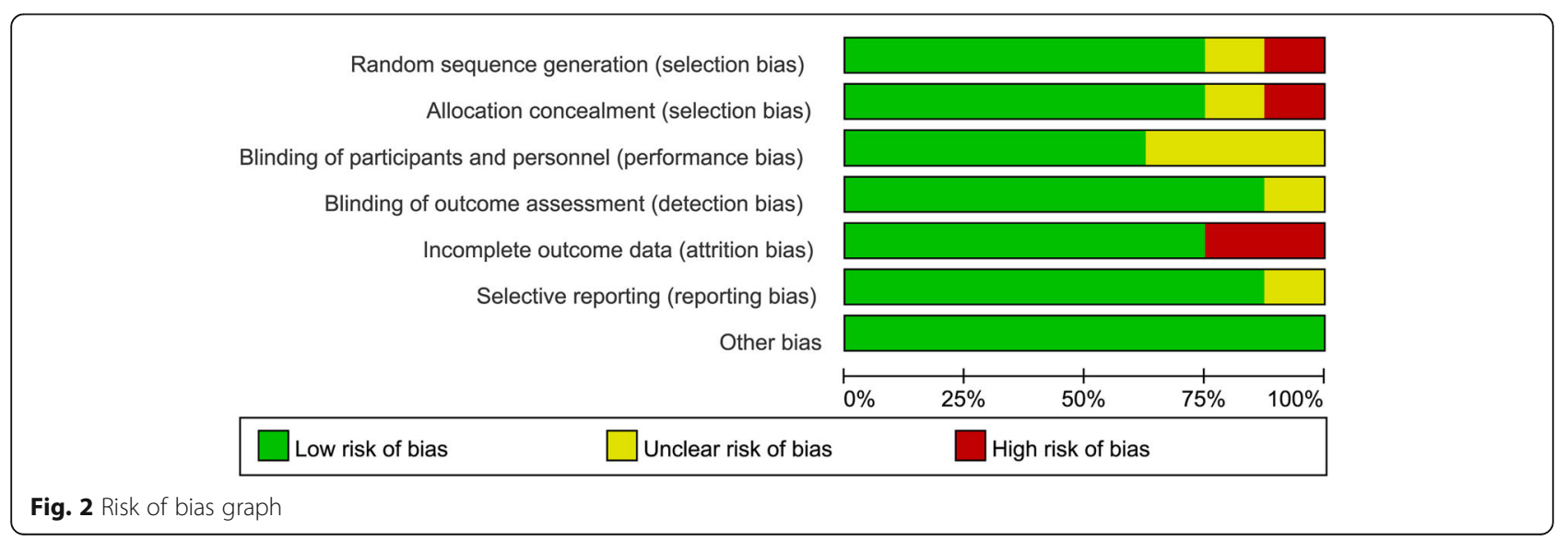




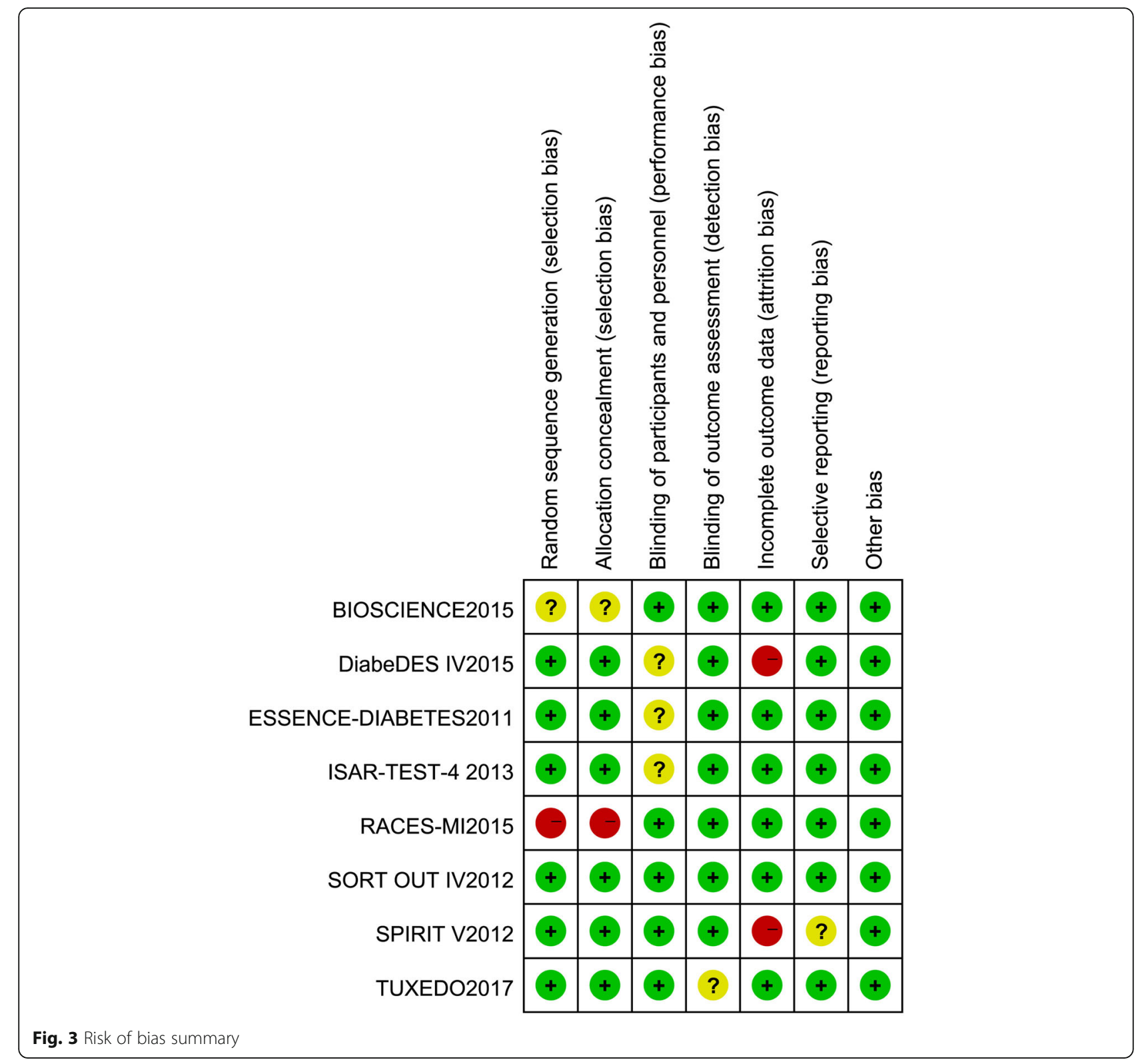

difference in cardiac mortality was found between EES and SES $(\mathrm{RR}=0.81,95 \% \mathrm{CI}: 0.51-1.28, p=0.37)$ or EES and PES ( $\mathrm{RR}=0.55,95 \% \mathrm{CI}: 0.12-2.57, p=$ 0.44) (Fig. 6b). A low level of statistical heterogeneity was found in the analysis $\left(\mathrm{I}^{2}=0 \%\right.$ for both all-cause mortality and cardiac mortality comparisons).

\section{Myocardial infarction and stent thrombosis}

A lower MI rate was observed in the EES-treated patients than in the PES-treated patients $(\mathrm{RR}=$ 0.59, 95\% CI: $0.35-0.98, p=0.04)$. Furthermore, the MI rate of the EES-treated patients was lower than that of the pooled SES and PES data $(R R=0.65$,
95\% CI: 0.49-0.87, $p=0.003$ ) (Fig. 7a). In addition, EES showed promising efficacy in the prevention of $\mathrm{ST}$, as it induced a lower $\mathrm{ST}$ rate than SES $(\mathrm{RR}=$ $0.53,95 \% \mathrm{CI}: 0.28-0.98, \mathrm{p}=0.04)$ or PES (RR = 0.18 , 95\% CI: $0.07-0.51, p=0.001)$ or the pooled SES and PES (RR $=0.39,95 \%$ CI: 0.23-0.67, $p=$ 0.0006) (Fig. 7b).

\section{Sensitivity and subgroup analysis}

After we used the fixed effect model, some of our previously nonsignificant results became statistically significant, such as EES vs SES for in-stent LLL and myocardial infarction and EES vs PES for ST. Therefore, 


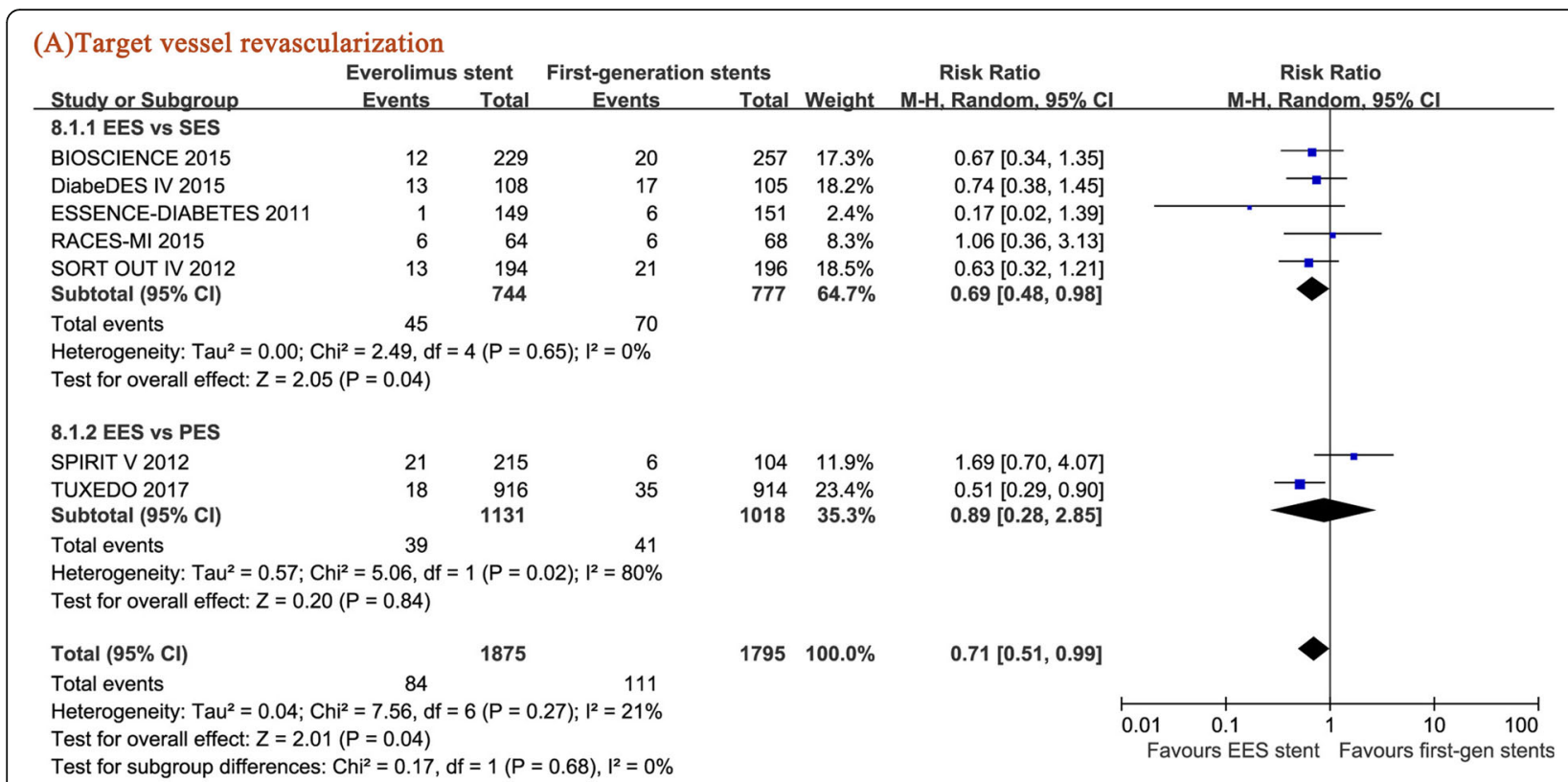

(B)Target lesion revascularization

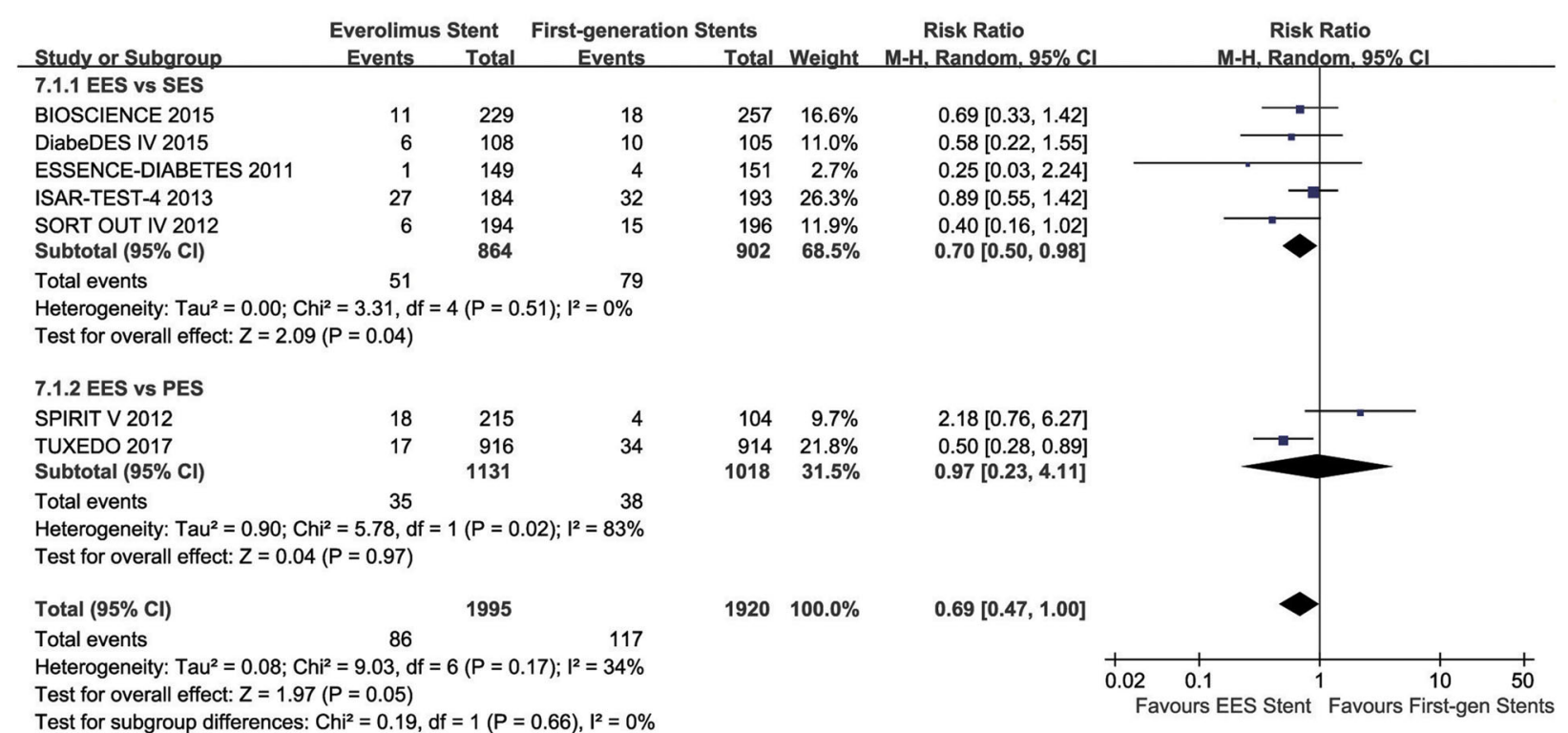

Fig. 4 Forest plots of the pooled risk ratios for (a) target vessel revascularization (TVR) and (b) target lesion revascularization (TLR)

we performed subgroup analysis for TLR and ST according to the DAPT duration ( $<12$ months or $=12$ months), the follow-up time ( $<24$ months or $\geq 24$ months) and insulin application. For the comparison of the EES-treated versus PES-treated patients and the EES-treated versus SES-treated DM patients, the TLR rate was lower in the subgroup with a 12-month DAPT duration than that with a DAPT duration less than 12 months $(p=0.01)$. Nevertheless, no significant difference in the TLR rate and the ST rate was found between the remaining subgroups (all $p>0.05$ ) (Table 2).

\section{Heterogeneity analysis}

High heterogeneity was found in the EES vs PES group when we performed the analysis of TLR and TVR (Fig. 4). Since only two studies met the included criteria of this group, sensitivity analysis was not applicable. In addition, relatively high heterogeneity was found in the EES vs SES group when evaluating instent LLL. However, no change in the merged effect of in-stent LLL and in-segment LLL (both $P<0.05$ ) was observed in the sensitivity analysis after removing RCT DiabeDES IV [14]. Furthermore, we could not 


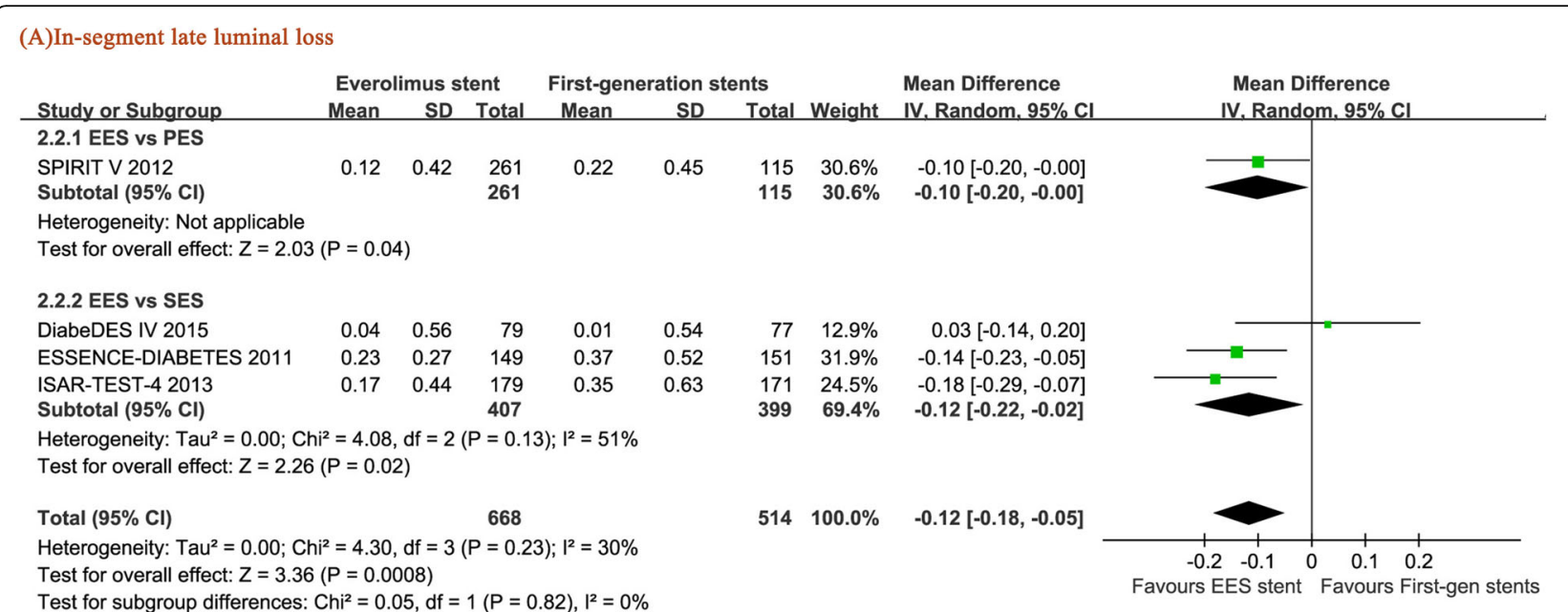

(B)In-stent late luminal loss

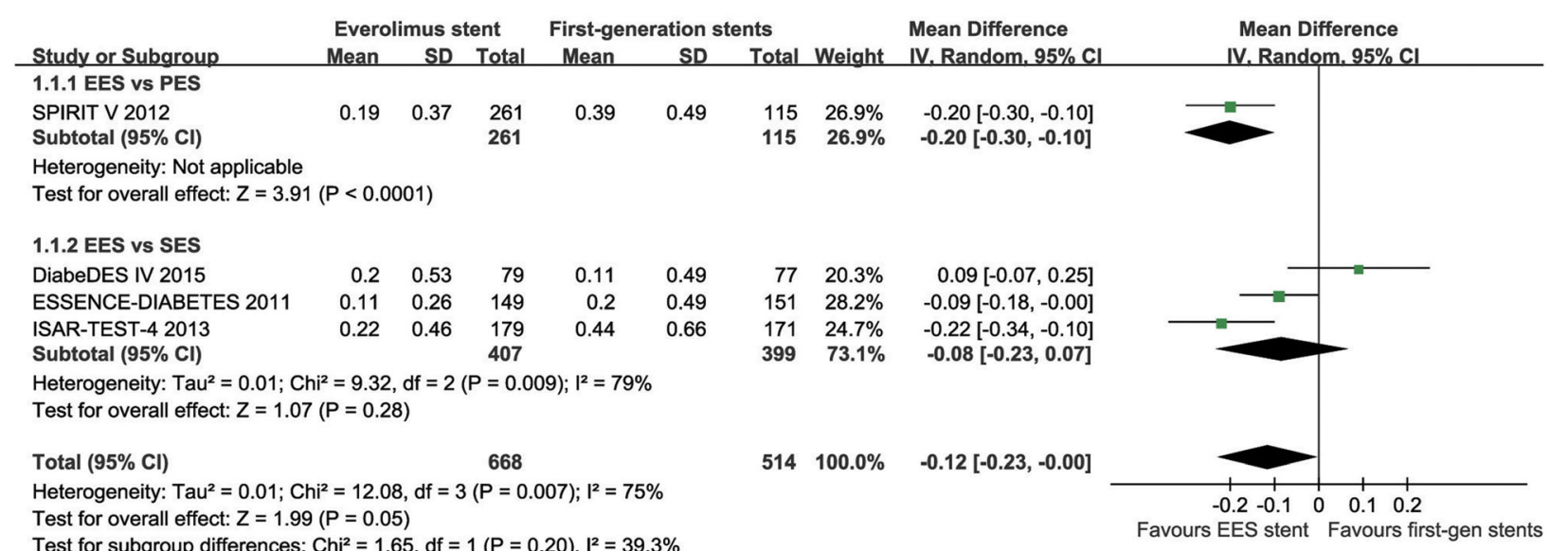

Fig. 5 Forest plots of the pooled risk ratios for (a) in-segment late luminal loss (in-stent LLL) and (b) in-stent late luminal loss (in-stent LLL)

find the source of heterogeneity after carefully reviewing the RCT DiabeDES IV [14].

\section{Discussion}

To date, drug-eluting stents have been recommended as the primary choice for patients with coronary heart syndrome undergoing PCI because they have a better performance than bare metal stents (BMS) in reducing the recurrence rate, myocardial infarction rate, and inflammatory response in patients, which would therefore prolong patient survival.

In the past, sirolimus and paclitaxel were among the most common drugs for DES. Everolimus, an analogue of sirolimus, inhibits FRAP protein expression and intima proliferation. To date, many studies have demonstrated that EES shows advantages over SES and PES in longterm prognosis and has become the most widely used stent in Europe and the United States [17, 18].
DM is an independent predictor of early ST that could induce some unique cardiovascular changes in patients, including intimal dysfunction, endothelial hyperproliferation, and platelet dysfunction, thus impairing vascular vasodilation and finally leading to poorer clinical outcomes [19]. Thus, the choice of stents is further complicated in DM patients. Many previous studies have found that compared to PES, SES induced lower levels of LLL and TLR and less endometrial hyperplasia in diabetic patients [20-22], indicating that the efficacy and safety of different kinds of DES for DM patients could vary.

More recently, according to large-scale meta-analysis and reviews, EES showed better efficacy and safety than other DES for patients due to their better postoperative blood flow reconstruction and lower occurrence of TLR and ST [23, 24]. However, the antiproliferative effect of EES could be attenuated due to the high glucose status in diabetic patients [18].. As more complications and 


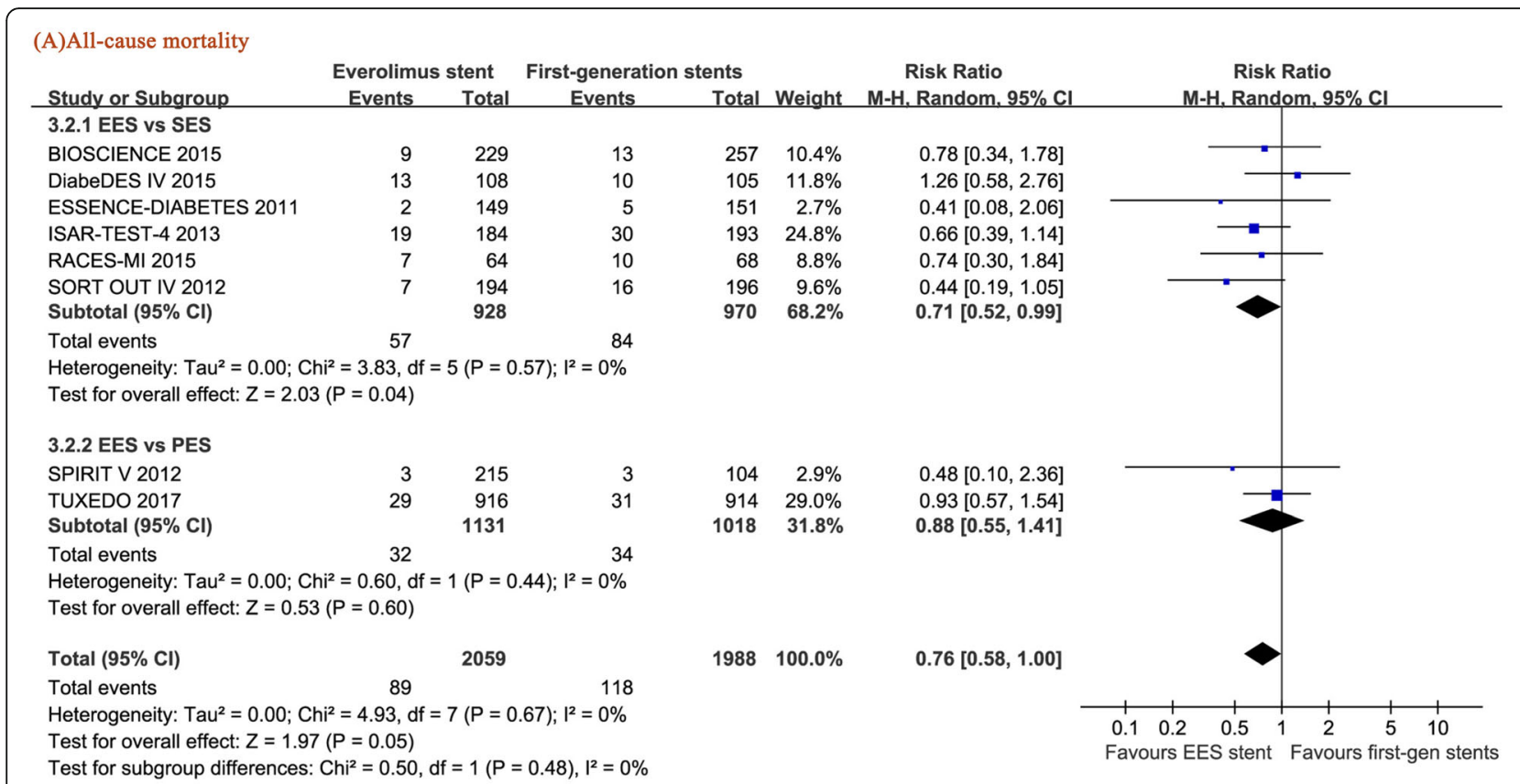

(B)Cardiac mortality

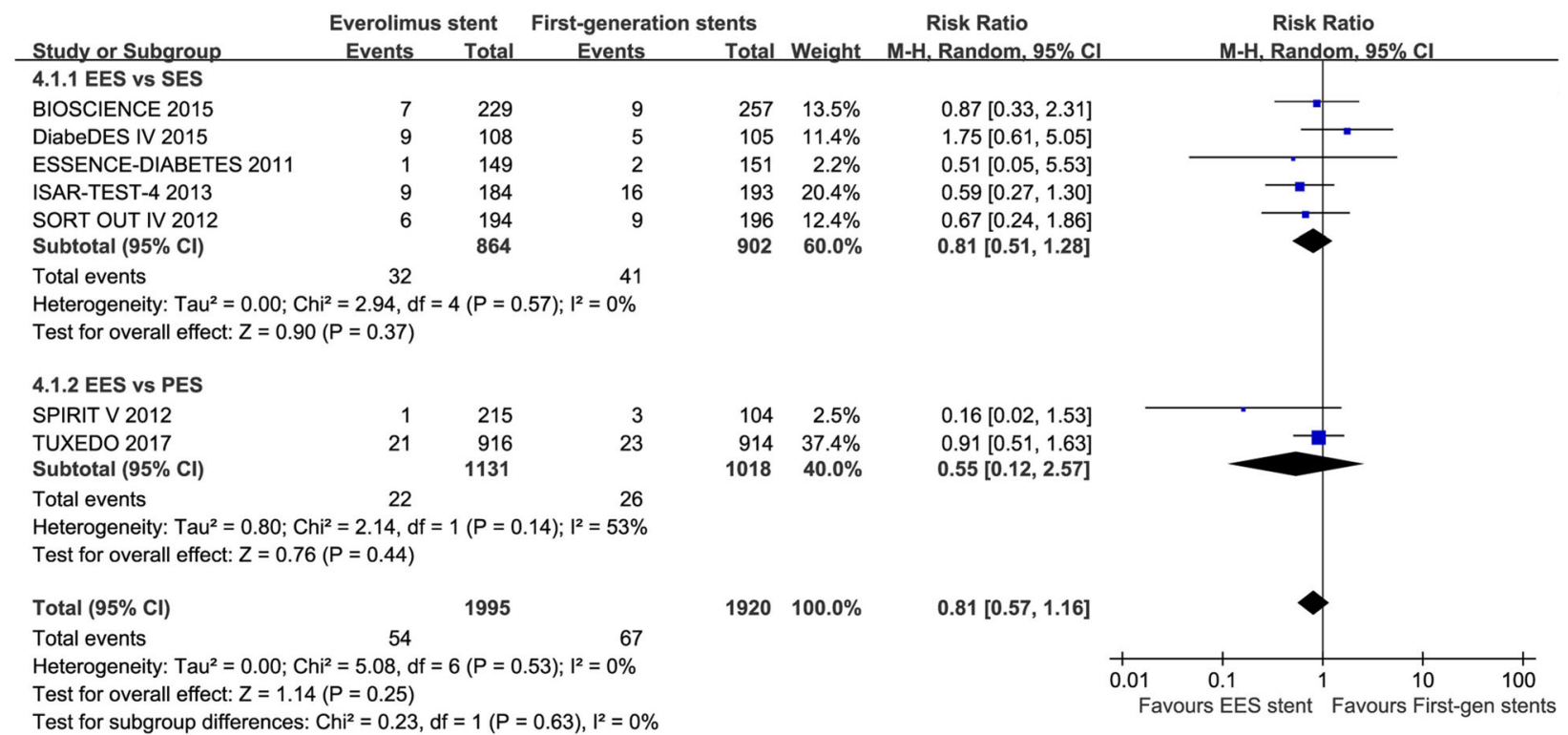

Fig. 6 Forest plots of the pooled risk ratios for (a) all-cause mortality and (b) cardiac mortality

higher mortality were found in DM patients undergoing PCI than other patients undergoing PCI, identification of a more suitable stent is urgently needed.

Thus, our current study focused on which kind of DES among EES, PES and SES should be first recommended for DM patients. This meta-analysis revealed that EES is more effective and safer than SES and PES in the treatment of diabetic patients. Compared with SES, EES reduced the occurrence of TLR and TVR by 30 and $31 \%$, respectively. When the DAPT duration was 12 months, the reduction in TLR was more obvious (34\%). LLL has been considered another indicator of the anti-restenosis effect and effectiveness of stents after PCI [25-27]. Instent LLL and in-segment LLL reflect the extent of intimal hyperplasia and the antiproliferative capacity of stents; thus, both of them could be used as predictors of restenosis [28, 29]. According to our results, EES induced 20\% less in-stent LLL than PES and 12 and 10\% 


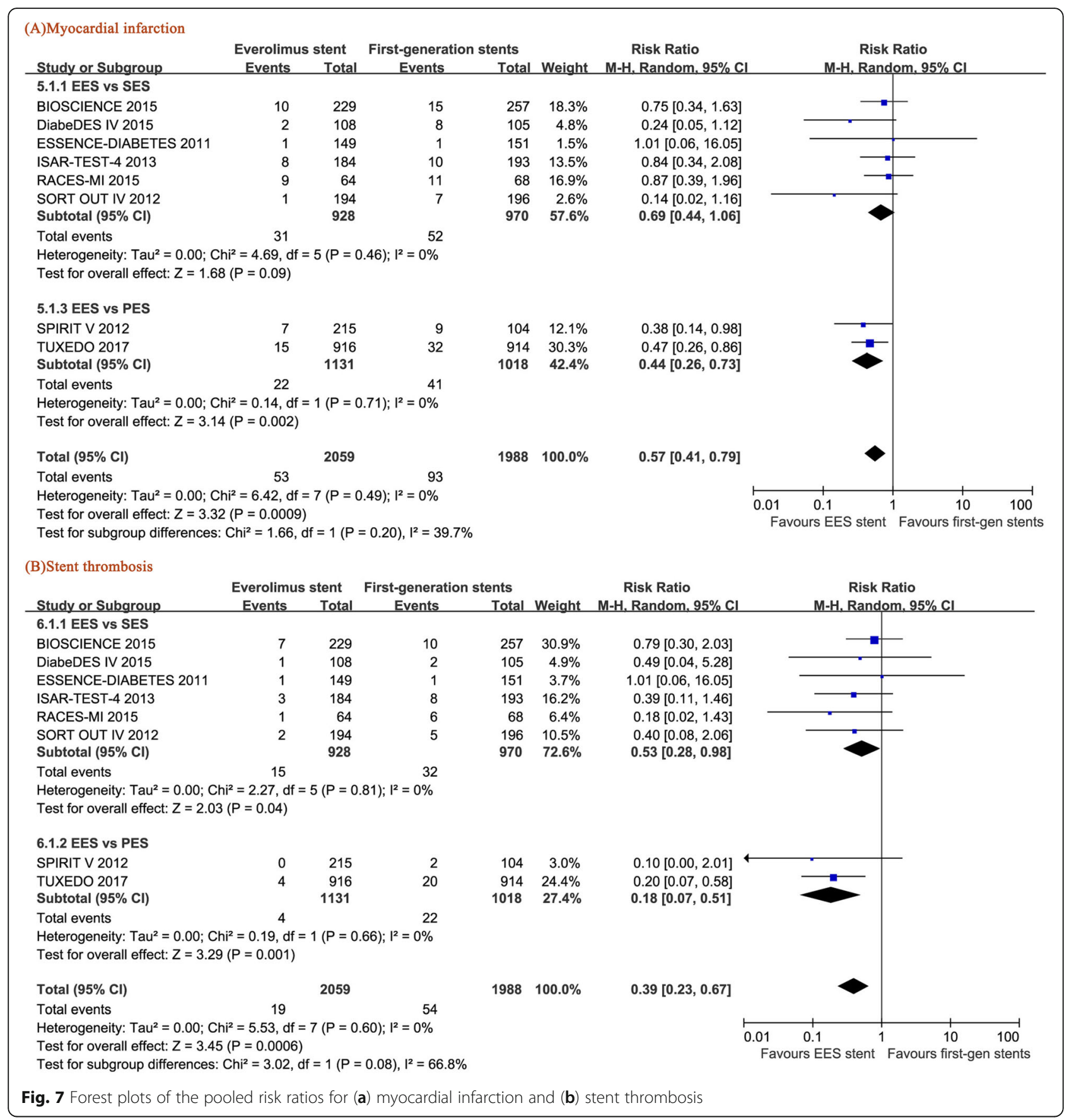

less in-segment LLL than SES and PES, respectively. These data suggested a better anti-restenosis effect of EES. In addition, EES has shown outstanding long-term advantages over SES in the treatment of DM patients, as it significantly reduced all-cause mortality by $29 \%$. Moreover, EES reduced the rate of MI by $56 \%$ compared with PES. Furthermore, the ST rate was 47 and $72 \%$ lower in the EES-treated patients than in the SES-treated and PES-treated patients, respectively.
Of note, MACE has been used as the main indicator of safety in some previous meta-analyses that focused on the differences between first- and secondgeneration DES [30]. However, as there is no clear and unified standard for MACE, the results of RCTs could be substantially different if different judgement standards of MACE were employed [31]. Therefore, we did not employ MACE as a safety indicator in this meta-analysis. 
Table 2 Subgroup analyses based on the data of TLR and stent thrombosis; CI - confidence interval, DAPT - dual antiplatelet therapy, RR - risk ratio, TLR - target lesion revascularization

\begin{tabular}{|c|c|c|c|c|c|c|}
\hline \multirow[b]{2}{*}{ Subgroups } & \multicolumn{3}{|c|}{ Stent thrombosis } & \multicolumn{3}{|l|}{ TLR } \\
\hline & No. of studies & RR $(95 \% \mathrm{Cl})$ & Interaction $P$ value & No. of studies & RR $(95 \%$ Cl) & Interaction $\mathrm{P}$ value \\
\hline$\leq 30 \%$ patients with insulin therapy & 2 & $0.34(0.03,3.43)$ & 0.91 & 2 & $0.92(0.12,7.32)$ & 0.74 \\
\hline$>30 \%$ patients with insulin therapy & 5 & $0.39(0.22,0.70)$ & & 4 & $0.65(0.46,0.91)$ & \\
\hline DAPT duration $=6$ months & 2 & $0.32(0.09,1.05)$ & 0.69 & 2 & $1.09(0.67,1.76)$ & 0.01 \\
\hline DAPT duration $=12$ months & 6 & $0.42(0.23,0.75)$ & & 5 & $0.50(0.34,0.74)$ & \\
\hline$<$ 24-months follow-up & 4 & $0.61(0.28,1.30)$ & 0.12 & 4 & $0.72(0.32,1.58)$ & 0.9 \\
\hline 224-months follow-up & 4 & $0.26(0.13,0.55)$ & & 3 & $0.68(0.46,1.00)$ & \\
\hline
\end{tabular}

\section{Limitations}

According to the Cochrane Handbook for Systematic Reviews of Interventions, it is recommended that at least 10 studies be included in the funnel plot; otherwise, it would be not sufficient to objectively evaluate the symmetry of the funnel plot. Thus, as the present study only included 8 RCTs, the funnel plot was not used.

Furthermore, we could not find the source of heterogeneity after carefully reviewing the RCT DiabeDES IV [14]. We presumed that this hetrogeneity may be due to the limited number of studies included. Therefore, we used random effect models to ensure that the research conclusions can be interpreted with caution. Subgroup analysis based on DAPT duration demonstrated that TLR was significantly higher in the subgroups with a DAPT duration of 12 months than in those with DAPT duration of 6 months $(p=0.01)$ (Table 2). However, due to the limited number of studies and samples included, large-scale studies are needed to further clarify the preliminary conclusions in this report. Moreover, we did not have data about insulin treatment for the patients. However, studies have found that although a lower overall TLR rate has been demonstrated in the EES group than in the PES group during the 2-year follow-up, only the DM patients without insulin treatment could take advantage of EES $[10,18]$.

As these above limitations might lead to some research biases, more RCTs with abundant sample numbers are urgently needed for a more convincing research conclusion.

\section{Conclusion}

Compared with nondiabetic patients, DM patients have a higher risk of severe multivascular coronary blood flow disorders and worse prognosis. The present metaanalysis proved that EES has better safety and efficacy for DM patients than SES and PES and showed good potential to be the first choice of DES for those patients.

\section{Abbreviations}

EES: Everolimus-eluting stent; SES: Sirolimus-eluting stents; PES: Paclitaxeleluting stents; CVD: Coronary vascular disease; LLL: Late luminal loss; MI: Myocardial infarction; ST: Stent thrombosis

\section{Acknowledgements}

Not applicable.

\section{Authors' contributions}

H.O. contributed to all steps, including study screening, data extraction, analysis, and manuscript preparation; X.Z. participated in data extraction, data analysis, and manuscript writing and made the tables; C.Z. and L.S. wrote the protocol and participated in title and abstract screening, full-text screening and data extraction; J.X. searched the databases and participated in title and abstract screening, full-text screening and data extraction; H.Z. and X.S. reviewed the protocol and participated in title and abstract screening and data extraction; Z.T. proposed the search terms, managed the work, and reviewed data extraction, data analysis and the manuscript; J.H. provided general supervision and reviewed data extraction, data analysis and the manuscript. The authors read and approved the final manuscript.

\section{Funding}

This work was supported by Shenzhen Science and Technology Project (JCYJ20170307155244629) and Guangdong Province Traditional Chinese Medicine Bureau Project (20182125).

\section{Availability of data and materials}

Not applicable.

\section{Declarations}

Ethics approval and consent to participate

Not applicable.

\section{Consent for publication}

Not applicable.

\section{Competing interests}

We declare that we do not have any commercial or associative interest that represents a conflict of interest in connection with the work submitted.

Received: 29 May 2020 Accepted: 31 March 2021

Published online: 17 April 2021

References

1. Codner P, Motivala A. Coronary stents in diabetic patients: state of the knowledge. Curr Cardiol Rep. 2017;19(4):28. https://doi.org/10.1007/s11886017-0837-y.

2. Hong SJ, Kim MH, Ahn TH, Ahn YK, Bae JH, Shim WJ, et al. Multiple predictors of coronary restenosis after drug-eluting stent implantation in patients with diabetes. Heart. 2006;92(8):1119-24. https://doi.org/10.1136/ hrt.2005.075960.

3. Kumar R, Lee TT, Jeremias A, Ruisi CP, Sylvia B, Magallon J, et al. Comparison of outcomes using Sirolimus-eluting stenting in diabetic versus nondiabetic patients with comparison of insulin versus non-insulin therapy in the diabetic patients. Am J Cardiol. 2007;100(8):1187-91. https://doi.org/10.1016/ j.amjcard.2007.05.038.

4. Preis SR, Hwang SJ, Coady S, Pencina MJ, D'Agostino RB Sr, Savage PJ, et al. Trends in all-cause and cardiovascular disease mortality among women and 
men with and without diabetes in the Framingham heart study, 1950-2005. Circulation. 2009;119(13):1728-35. https://doi.org/10.1161/CIRCULATIONA HA. 108.829176.

5. Kedhi E, Joesoef KS, McFadden E, Wassing J, van Mieghem C, Goedhart D, et al. Second-generation everolimus-eluting and paclitaxel-eluting stents in real-life practice (COMPARE): a randomised trial. Lancet. 2010;375(9710):2019. https://doi.org/10.1016/S0140-6736(09)62127-9.

6. Park KW, Chae IH, Lim DS, Han KR, Yang HM, Lee HY, et al. Everolimuseluting versus sirolimus-eluting stents in patients undergoing percutaneous coronary intervention: the EXCELLENT (efficacy of Xience/Promus versus cypher to reduce late loss after stenting) randomized trial. J Am Coll Cardiol. 2011;58(18):1844-54. https://doi.org/10.1016/j.jacc.2011.07.031.

7. Grube E, et al. The SPIRIT V diabetic study: a randomized clinical evaluation of the XIENCE $V$ everolimus-eluting stent vs the TAXUS Liberte paclitaxeleluting stent in diabetic patients with de novo coronary artery lesions. Am Heart J. 2012;163:867-875 e861. https://doi.org/10.1016/j.ahj.2012.02.006.

8. Higgins J P T, Green S. Cochrane handbook for systematic reviews of interventions. Chichester: Hoboken [J]; 2008. https://doi.org/10.1002/97804 70712184.

9. Kereiakes DJ, Cutlip DE, Applegate RJ, Wang J, Yaqub M, Sood P, et al. Outcomes in diabetic and nondiabetic patients treated with everolimus-or paclitaxel-eluting stents: results from the SPIRIT IV clinical trial (clinical evaluation of the XIENCE V Everolimus eluting coronary stent system). J Am Coll Cardiol. 2010;56(25):2084-9. https://doi.org/10.1016/j.jacc.2010.10.006.

10. Franzone A, et al. Clinical outcomes according to diabetic status in patients treated with biodegradable polymer sirolimus-eluting stents versus durable polymer everolimus-eluting stents: prespecified subgroup analysis of the BIOSCIENCE trial. Circ Cardiovasc Interv. 2015;8. https://doi.org/10.1161/ CIRCINTERVENTIONS.114.002319.

11. Jensen LO, Thayssen P, Junker A, Maeng M, Tilsted HH, Kaltoft A, et al. Comparison of outcomes in patients with versus without diabetes mellitus after revascularization with everolimus- and sirolimus-eluting stents (from the SORT OUT IV trial). Am J Cardiol. 2012;110(11):1585-91. https://doi.org/1 0.1016/j.amjcard.2012.07.022.

12. Kim WJ, et al. Randomized comparison of everolimus-eluting stent versus sirolimus-eluting stent implantation for de novo coronary artery disease in patients with diabetes mellitus (ESSENCE-DIABETES): results from the ESSE NCE-DIABETES trial. Circulation. 2011;124:886-92. https://doi.org/10.1161/ CIRCULATIONAHA. 110.015453.

13. Kufner S, Byrne RA, Mehilli J, Massberg S, Birkmeier KA, Schulz S, et al. Secondversus first-generation "Limus"-eluting stents in diabetic patients with coronary artery disease: a randomized comparison in setting of ISAR-TEST-4 trial. Catheter Cardiovasc Interv. 2013;82(6):E769-76. https://doi.org/10.1002/ccd.24741.

14. Maeng M, Baranauskas A, Christiansen EH, Kaltoft A, Holm NR, Krusell LR, et al. A 10-month angiographic and 4-year clinical outcome of everolimuseluting versus sirolimus-eluting coronary stents in patients with diabetes mellitus (the DiabeDES IV randomized angiography trial). Catheter Cardiovasc Interv. 2015;86(7):1161-7. https://doi.org/10.1002/ccd.25875

15. Kaul U, Bhagwat A, Pinto B, Goel P, Jagtap P, Sathe S, et al. Paclitaxel-eluting stents versus everolimus-eluting coronary stents in a diabetic population: two-year follow-up of the TUXEDO-India trial. Eurolntervention. 2017;13(10): 1194-201. https://doi.org/10.4244/eij-d-17-00333.

16. Di Lorenzo E, et al. Randomized comparison of everolimus-eluting stents and sirolimus-eluting stents in patients with ST elevation myocardial infarction: RACES-MI trial. JACC Cardiovasc Interv. 2014;7(8):849-56. https:// doi.org/10.1016/j.jcin.2014.02.016

17. Serruys PW, et al. A randomised comparison of an everolimus-eluting coronary stent with a paclitaxel-eluting coronary stent: the SPIRIT II trial. Eurolntervention. 2006;2:286-94.

18. Stone GW, Midei M, Newman W, Sanz M, Hermiller JB, Williams J, et al. Comparison of an everolimus-eluting stent and a paclitaxel-eluting stent in patients with coronary artery disease: a randomized trial. Jama. 2008;299(16): 1903-13. https://doi.org/10.1001/jama.299.16.1903.

19. Hammoud T, Tanguay J-F, Bourassa MG. Management of coronary artery disease: therapeutic options in patients with diabetes. J Am Coll Cardiol. 2000;36(2):355-65. https://doi.org/10.1016/S0735-1097(00)00732-4.

20. Jensen LO, Maeng M, Thayssen P, Christiansen EH, Hansen KN, Galloe A, et al. Neointimal hyperplasia after sirolimus-eluting and paclitaxel-eluting stent implantation in diabetic patients: the randomized diabetes and drugeluting stent (DiabeDES) intravascular ultrasound trial. Eur Heart J. 2008; 29(22):2733-41. https://doi.org/10.1093/eurheartj/ehn434.
21. Dibra A, Kastrati A, Mehilli J, Pache J, Schühlen $\mathrm{H}$, von Beckerath $\mathrm{N}$, et al. Paclitaxel-eluting or sirolimus-eluting stents to prevent restenosis in diabetic patients. N Engl J Med. 2005;353(7):663-70. https://doi.org/10.1056/NEJMoa 044372.

22. Billinger M, Beutler J, Taghetchian KR, Remondino A, Wenaweser P, Cook S, et al. Two-year clinical outcome after implantation of sirolimus-eluting and paclitaxel-eluting stents in diabetic patients. Eur Heart J. 2008;29(6):718-25. https://doi.org/10.1093/eurhearti/ehn021.

23. Kleinbongard P, Böse D, Konorza T, Steinhilber F, Möhlenkamp S, Eggebrecht $\mathrm{H}$, et al. Acute vasomotor paralysis and potential downstream effects of paclitaxel from stents implanted for saphenous vein aortocoronary bypass stenosis. Basic Res Cardiol. 2011;106(4):681-9. https://doi. org/10.1007/s00395-011-0177-9.

24. Bangalore S, Kumar S, Fusaro M, Amoroso N, Kirtane AJ, Byrne RA, et al. Outcomes with various drug eluting or bare metal stents in patients with diabetes mellitus: mixed treatment comparison analysis of 22844 patient years of follow-up from randomised trials. Bmj. 2012;345(aug10 1):e5170. https://doi.org/10.1136/bmj.e5170.

25. Windecker, S.m, Remondino A., Eberli F. R., Jüni P., Räber L., Wenaweser P., Togni M., Billinger M., Tüller D., Seiler C., Roffi M., Corti R., Sütsch G., Maier W. , Lüscher T., Hess O. M., Egger M., Meier B. Sirolimus-eluting and paclitaxeleluting stents for coronary revascularization. N Engl J Med. 2005;353(7):653662. https://doi.org/10.1056/NEJMoa051175.

26. Hoye A, Tanabe K, Lemos PA, Aoki J, Saia F, Arampatzis C, et al. Significant reduction in restenosis after the use of sirolimus-eluting stents in the treatment of chronic total occlusions. J Am Coll Cardiol. 2004;43(11):1954-8. https://doi.org/10.1016/j.jacc.2004.01.045.

27. Schofer J, Schlüter M, Gershlick AH, Wijns W, Garcia E, Schampaert E, et al. Sirolimus-eluting stents for treatment of patients with long atherosclerotic lesions in small coronary arteries: double-blind, randomised controlled trial (E-SIRIUS). Lancet. 2003;362(9390):1093-9. https://doi.org/10.1016/S0140-6736(03)14462-5.

28. Mauri L, Orav EJ, O'Malley AJ, Moses JW, Leon MB, Holmes DR Jr, et al. Relationship of late loss in lumen diameter to coronary restenosis in sirolimus-eluting stents. Circulation. 2005;111(3):321-7. https://doi.org/10.11 61/01.CIR.0000153356.72810.97.

29. Pocock SJ, Lansky AJ, Mehran R, Popma JJ, Fahy MP, Na Y, et al. Angiographic surrogate end points in drug-eluting stent trials: a systematic evaluation based on individual patient data from 11 randomized, controlled trials. J Am Coll Cardiol. 2008;51(1):23-32. https://doi.org/10.1016/j.jacc.2007.07.084.

30. Bavishi C, Baber U, Panwar S, Pirrotta S, Dangas GD, Moreno P, et al. Efficacy and safety of everolimus and zotarolimus-eluting stents versus firstgeneration drug-eluting stents in patients with diabetes: a meta-analysis of randomized trials. Int J Cardiol. 2017;230:310-8. https://doi.org/10.1016/j.jica rd.2016.12.116.

31. Kip KE, Hollabaugh K, Marroquin OC, Williams DO. The problem with composite end points in cardiovascular studies: the story of major adverse cardiac events and percutaneous coronary intervention. J Am Coll Cardiol. 2008;51(7):701-7. https://doi.org/10.1016/j.jacc.2007.10.034.

\section{Publisher's Note}

Springer Nature remains neutral with regard to jurisdictional claims in published maps and institutional affiliations.

Ready to submit your research? Choose BMC and benefit from:

- fast, convenient online submission

- thorough peer review by experienced researchers in your field

- rapid publication on acceptance

- support for research data, including large and complex data types

- gold Open Access which fosters wider collaboration and increased citations

- maximum visibility for your research: over $100 \mathrm{M}$ website views per year

At $\mathrm{BMC}$, research is always in progress.

Learn more biomedcentral.com/submissions 